\title{
Applications Research of Dancing Costumes in National Dance
}

\author{
Zhang Wei \\ Tarlac State University, Tarlac city, Philippines \\ Zhangwei@163.com
}

Keyword: dancing costumes, national dance, applications research.

\begin{abstract}
As a kind of elegant art and popular art, dance has a long history and is loved by many different races. National dance is also considered as the essence of the national culture. In the national dance, dancing costumes can help to reflect the role, express the contents and embody the depth of the dance. This paper analyzes the applications of the color, material and structure of dancing costumes in national dance in order to give references to the relative researchers.
\end{abstract}

\section{Introduction}

Dancing costumes generally refer to the design and selection of clothing, shoes and accessories in certain dancing occasions. The concept of dancing costume is divided into broad sense and narrow sense, and the narrow sense dance costume is the decoration of the dance costume. The generalized dance dress is the dance of the service and dance of the two part of the act. The paper involves the dance costumes is the concept of generalized, it contains using the first service, foot wear, a variety of physical service, including comprehensive modification of the whole shape of the dancers, such as the use of headdress, necklace, brooch, waist, arm ornaments, wristlet, foot ornaments and other kinds of jewelry, design patterns, color collocation and gold and silver beads. It also includes dancer's hair, face, hair, makeup and other grooming. As an important symbol of the national spirit and cultural life, the national dance is an indispensable part of the national culture. Each nation is blooming with unique splendor. Each flower has own blooming, every nation has their own ancient dance, court dance and other forms of dance is a folk dance. National dance can reflect a nation's customs, human nature and ethnic characteristics.

\section{Functions of National Dancing Costumes}

\section{Reflect Characteristics of the Dance Role}

In the dance, the basic function of the dancing costumes is to reflect the characteristics of the dance role as the actors themselves cannot directlycompletely explain the roles to the audience. If the actors only dressed in ordinary form clothing dancing on the stage, whether performers was how hard, actor of stage skills how solid, the actor's emotional expression how in place, audience is not well understood the actor to watch as the content, not very good into dance to bring the audience to the atmosphere. And through the actor's own changes in the body image of the packaging, you can play a role in the identity of the identity of the identity of the era background. It can be said that one of the outstanding works of dance, must be complete and proper dress contrast to the, these clothes continuously to the audience convey information about dance, laid the dance tone, reflects the feature of the characters in the dance roles. Not only such, dance costumes also for the audience to create better the effect of the story, the audience have a stronger sense of substitution, so that the audience can be personally on the scene, practical to follow the actors into the story, following the actor's emotional ups and downs of the continuous changes, so the dance of the overall sense of contrast can play a role in rendering aptly. It can be said that the dance costumes is very importantfor the emotional expression of the actors and the audience.

\section{Express Contents of the Dance Works}

Dance performance is different with language performance. It can only rely on the performance of the dancer's body movements to convey the central idea in the works of topics and content. Dancing costumes play a role in expressthe content to a very effective contrast effectin the 
expression of dance workso that the entire dance works look more fresh and vivid. Good clothing for dancer better stretching plays a very important role, still hypothetical if dancers wearing only ordinary physical dance performance service, regardless of the dancer itself has many strong dance skills, regardless of the dancers express how vivid, but many places still not be able to perfect performance, not have the trappings of a foil, many originally made up very beautiful action it is not natural. Clothing can make dancers make movements more beautiful, more artistic. It also auxiliary dancer better interpretation of dance works, so that the audience at a glance, clear dancers portrayed characters. For example the famous dance artist Yang by the creation of a solo dance called the frozen snake, a lively and vivid dance, in one fell swoop, with very high artistic ornamental, in the dance, dancers dressed in cold tones of blue dress, decorated with silver sequined dress, sequins along the dancer arm up to his shoulder, like a burgeoning snake, in addition to dance actor flexible dancing, really like is a frozen snake cried in despair. Dancing costumes can also play a role in transmitting the purport of the works in the dance which can help dancers express the content to the maximized degree.

\section{Embody Depth of the Dance Art}

The depth of the dance art means the artistic conception which is in the dance of the dress itself or the beauty of the dance movements. The art of dance costumes is based on the role of dance costumes, or by a certain kind of meaning. In the art of dance costumes, contains many artistic elements, such as: the plastic arts, the art of painting, folk arts and other can dance costumes is on the stage of a small and rich encyclopedia said. So, the audience watching the entire dance performance, in fact, the dancers who wear costumes, but also dance performances in the audience can enjoy a very important part of. The audience can in the middle of the dancer's dress that a lot of information, both dancers' personal characteristics, represented the dance that conveys to the audience out of spirit, and dance in national characteristics. The audience can get a glimpse of more accurate evaluation of the dance from the details of clothing.

\section{Applications of Dancing Costumes in National Dance}

\section{Applications of Dancing Costumes' Color}

Dance art expresses feelings by strong lyrical and romantic feelings of the dance itself.Many nationalsare good at sing and dance,an have a good command of dance to express feelings of national, hate people's emotions through the body language of dance will deeply love imprint is engraved on my heart yearning for release a better future feelings fully, and the color is supplement and reappearance of the emotion. The vision of people of different hue feel different, blue and green stimulus is moderate, and the red color such as orange easily lead to visual excitement. The former belongs to the cold tone; the latter belongs to the warm color. In addition, dark, heavy, light color easy to expand. There will be bright in the sense of feeling soft, dark is far from being hard. Light color can be any combination. Black and white gray is the color of the security. They can almost match any other colors. Brown is relatively dangerous, except for black and white ash three kinds of security, not too easy to match with other colors. There is a complementary color, called complementary relationship. Clothing should pay attention to complementary color. Complementary color is too strong, not easy to combine the harmonious aesthetic effect. The complementary relationship refers to the relationship between each color and relative color. If it is dark, color is strong, it should be carefully matched, make it hard to appear stiff. Danceclothing designer clothing is black headband crown, dressed in white clothes to the deep blue.The white and black fan in hands and the white boat shoes can reflect the elegant and solemn of the dance.

\section{Applications of Dancing Costumes' Material}

Dance costumes made of different materials have different sense of art. Different materials also give the audience different visual feeling to help actors and actresses better shape their role, heighten the feeling and the theme of the dance of the whole. After the basic dress style and the color of the dress, the choice of material is the key factor to the success of the dance costume. In material selection, to dance according to transfer different content and minority of its own characteristics to determine, for example Tibetan Dancecostumes, use thin robe yarn as the main 
part of the clothing, and the imitation flash the hem of the robe yarn at the end of, this design can make the dancer dancing after formation of run light dancing but drooping at the bottom of the unique aesthetic, highlighting the national characteristics of the Tibetan dance, the impression profound. Material factors have played an indelible role in the expression of the theme of dance works.

\section{Applications of Dancing Costumes' Structure}

The structure of dance costume must be coordinated with the movement range of the dancers, and the structure of the dress will not hinder the movement of the actors. Dance in the presentation of its artistic characteristics of a certain kind of requirements, that is, the clothing of the dancers in the first to help to show the beauty of the body, but also help to show the dynamic beauty. In the selection and design of the dancing dress, make sure that dance costumes can ensure the dancers were acting can move freely and in dancers perform some larger movements of the dance movements can also ensure the clothing itself is not damaged. The rice dance "by Korean dance common cover hand, carry deuce, top hand, carry back hand, hand around the wrist and hand movements become the core actions of the dance, through the exquisite take scoop rice action full performance of the Korean women who loves life and worked hard. And Korean sleeved jacket contributed to these upper extremity movements without limitation and dance costumes is reflected more prominent. Actors wore Korean clothing in the most traditional color is white, no buttons, use cloth to tie a knot, the cuffs, skirts, armpit inlaid with colorful Satin Edge, lower body clothing to dress and apron, see wearing a small jacket, a full-length skirt which swept the ground, collar hanging streamers of Korean girls dancing lightly and beautiful image, in turnaround cranes wings dancing in refined thrives on the Korean national spirit. The applications of the dancing costumes' structure can make the dance more perfect and more vivid.

\section{Conclusion}

There are regional, cultural, history and aesthetic values differences in national dancing of each nation in the world. However, it's generally accepted the dance costumes is the most vivid and visual forms of dance works and play a very important part in the national dance. We believe that with the development of dancing costumes, national dance will become better and better.

\section{References}

[1] Zhang Wanlin,Art Design Feature of Dress Adornment for National Dance in Theatre, J. Art \&Design. 2008(9):86-88

[2] Dai Gang,"Ancestry" \& "Change" in Dancing Costumes of National Minorities, J. Art \& Design. 2014(12):92.

[3] Yu Yan, The Cultural Connotation Refracted by the Art Character of the National Dancing Costumes, J. Journal of Wuhan Textile S.n.T. Institute. 2004(3):34- 36

[4] Lu Zhao, Wang Ting. Functional Evolvement and Cultural Connotation of Chinese Ancient Dancing Costumes, J.Journal of Xi'an Technological University. 2014(7):592-597. 